\title{
An Isocratic Method for Quantification of Valproic Acid and Its Related Impurities Using Ion Pair Reagent by Ultraperformance Liquid Chromatography
}

\author{
Rakshit Thakkar, Hitesh Saravaia, Mrunal Ambasana, Madhavi Patel, and Anamik Shah \\ National Facility for Drug Discovery, Department of Chemistry, Saurashtra University, Rajkot 360005, Gujarat, India \\ Correspondence should be addressed to Madhavi Patel, patel_madhavi25@yahoo.com
}

Received 26 October 2012; Accepted 15 November 2012

Academic Editors: S. De Marino and X. Guan

Copyright (C) 2012 Rakshit Thakkar et al. This is an open access article distributed under the Creative Commons Attribution License, which permits unrestricted use, distribution, and reproduction in any medium, provided the original work is properly cited.

A selective ultraperformance liquid chromatographic (UPLC) method for the quantification of valproic acid and its known related impurities using ion pair reagent has been developed. The method includes reversed-phase Acquity HSS T3 column with $100 \mathrm{~mm} \times 2.1 \mathrm{~mm}$ i.d. and $1.7 \mu$ particle size. The mobile phase consists of acetonitrile, $5 \mathrm{mM}$ 1-hexanesulphonic acid sodium salt, flow rate is $0.6 \mathrm{~mL} / \mathrm{min}$, and UV detection is performed at $215 \mathrm{~nm}$. A system suitability test (SST) was developed to govern the quality of the separation. The developed method has been validated further with respect to linearity, accuracy, precision, selectivity, LOD, LOQ, and Robustness.

\section{Introduction}

Valproic acid is chemically known as 2-propylpentanoic acid. Chemical structures of valproic acid and its pharmacopeialrelated impurities are given in Figure 1. Valproic acid (VPA) is a chemical compound that has found clinical use as an anticonvulsant and mood-stabilizing drug, primarily in the treatment of epilepsy, bipolar disorder, and less commonly, it is also used to treat migraine headaches and schizophrenia [1-4]. To our knowledge, there is no paper describing an ultraperformance liquid chromatographic (UPLC) method that allows the separation of valproic acid and its related known impurities in bulk drugs. However, there are the UPLC-MS/MS method for the simultaneous determination of valproic acid and other 21 antiepileptic drugs for the routine therapeutic drug monitoring [5]. Furthermore we have used an ion pair reagent to resolute the valproic acid and its impurities more specifically, that is 2-isopropylpentanoic acid which is a structural isomer of valproic acid. Some articles are available on isocratic HPLC methods for the determination of valproic acid [6-10]. Gas chromatographic and colorimetric methods are also available in the literature for quantification of valproic acid [11-15]. Methods for determination of valproic acid by HPLC, LC-MS, or LCMS/MS from biological matrix have also been published [16-26]. In addition, the capillary electrophoresis methods for the determination of valproic acid in different biological samples are also available [27-30]. Applying the above methods for quantification of impurities in a bulk valproic acid sample gives poor separation. Hence, the objective of this study is to develop a more selective LC method for the analysis of valproic acid and its related impurities. Besides this, it is accurate, precise, selective, robust, and linear with a reasonable analysis time. Furthermore, the developed method is applicable for the analysis of drug substances as well as commercially available drug products containing valproic acid. This work also deals with the validation of methods for the quantification of valproic acid and its impurities.

\section{Materials and Methods}

2.1. Reagents and Chemicals. HPLC grade acetonitrile (ACN) was purchased from Fisher Scientific (Leicester, UK). 1hexane sulphonic acid sodium salt anhydrous was procured from Spectrochem Pvt. Ltd. (India). Dematerialized water was further purified by filtering through Milli-Q Elix-3 


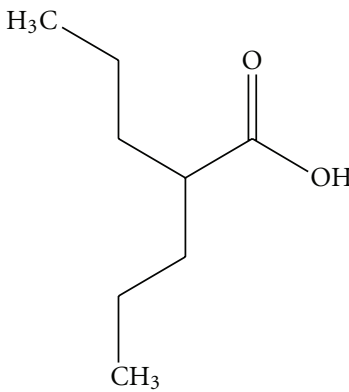

Valproic acid<smiles>CCCC(CC)C(=O)O</smiles>

2-Ethylpentanoic acid

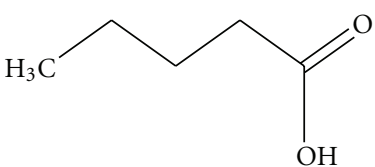

Pentanoic acid

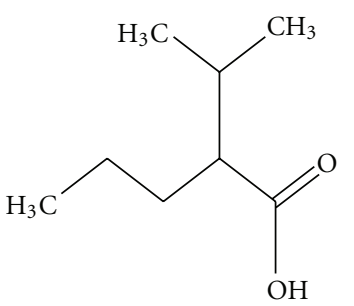

2-Isopropylpentanoic acid
FIGURE 1: Chemical structure of valproic acid and its related impurities.

purification system (Millipore, Milford, MA, USA). Valproic acid working standards and its related impurities were provided by Parth laboratories Pvt. Ltd.(Rajkot, India).

2.2. Preparation of Standard Solutions. A mixture of acetonitrile and water $(1: 1)$ was used as sample diluent for all sample preparations. Stock solution of valproic acid and its related impurities were prepared by dissolving accurately $100 \mathrm{mg}$ of each in $100 \mathrm{~mL}$ of sample diluent. Further pipette out $10 \mathrm{~mL}$ of this solution and dilute it up to $50 \mathrm{~mL}$ with sample diluent. This mixture contains $0.2 \mathrm{mg} / \mathrm{mL}$ valproic acid and its related impurities.

2.3. Instrumentation and Liquid Chromatographic Conditions. Waters Acquity UPLC (Switzerland) includes a binary solvent manager, a sample manager, PDA detector, and Empower 2.0 version software for data acquisition. A Waters Acqutiy HSS T3 column with $100 \mathrm{~mm} \times 2.1 \mathrm{~mm}$ i.d. and $1.7 \mu$ particle size was used to achieve the best separation; flow rate was set at $0.6 \mathrm{~mL} / \mathrm{min}$ while the injection volume was $10 \mu \mathrm{L}$. Based on the absorption maxima observed for all the four components, the detection wavelength was set at $215 \mathrm{~nm}$. The Spinco. Ltd. ultrasonic bath was used for the mobile phase and sample degassing. The Sartorius microbalance was used for the weighing purpose.

2.4. Mobile Phase Preparation. Mobile phase A consisted of $5 \mathrm{mM}$ 1-hexane sulphonic acid sodium salt anhydrous which was filtered through $0.22 \mu$ filter; mobile phase B consisted of acetonitrile (HPLC grade). The isocratic mode was set at $50: 50(\mathrm{~V} / \mathrm{V})$ ratio. The $5 \mathrm{mM}$ 1-hexane sulphonic acid sodium salt solution was prepared by dissolving $0.94 \mathrm{gm}$ of
TABLe 1: Data for method precision.

\begin{tabular}{lcccc}
\hline & \multicolumn{4}{c}{ Area } \\
Injection & PA & 2-EPA & 2-IsoPPA & VPA \\
\hline SET 01 & 224100 & 663931.5 & 672628.5 & 850128.5 \\
SET 02 & 212925.5 & 631144 & 639404.5 & 821765 \\
SET 03 & 213801 & 633675.5 & 641733.5 & 823815.5 \\
SET 04 & 214931.5 & 635104 & 643164.5 & 824633 \\
SET 05 & 218389.5 & 649573 & 654524 & 838073 \\
SET 06 & 218432.5 & 642225.5 & 642627.5 & 830001 \\
Mean & 217096.7 & 642608.9 & 649013.8 & 831402.7 \\
Std dev & 4134.018 & 12416.7 & 12715.01 & 10893.97 \\
\% CV & 1.904229 & 1.932233 & 1.959127 & 1.310312 \\
\hline
\end{tabular}

1-hexane sulphonic acid sodium salt in $1000 \mathrm{~mL}$ of purified water.

\section{Results and Discussion}

3.1. Method Development. The column selection is the most important part in the method development to achieve maximum sensitivity, resolution, and speed. After performing several trials on different columns, the maximum separations was achieved on Waters Acquity HSS T3 column with $100 \mathrm{~mm} \times 2.1 \mathrm{~mm}$ i.d. and $1.7 \mu$ particle size column. The compatibility of the method to ICH guideline was achieved by the isocratic elution at $50: 50(\mathrm{~V} / \mathrm{V})$ ratio of mobile phase $\mathrm{A}$ and $\mathrm{B}$. The selectivity of the valproic acid and its related impurities can be altered by changing the $\mathrm{pH}$ of the buffer. The premethod validation experiments were performed to avoid uncertainty at the time of method validation. The chromatograms of the standard and sample are given in Figure 2.

\subsection{Method Validation}

3.2.1. Accuracy. The accuracy experiment was performed by recovery study at three levels $150 \%, 100 \%$, and $50 \%$ of concentration. The recovery was found between 98 to $102 \%$ which is suitable to the ICH guideline Q2 (A).

3.2.2. Precision. The method precision was assessed using multiple preparations of a single sample. Six different preparations of valproic acid and its related impurities were analyzed in triplicate on the same day. The method precision data is shown in Table 1. New solutions were prepared and analyzed on each of two successive days for intermediate precision study which is given in Table 2 . The relative standard deviation values obtained for the peak areas of valproic acid, pentanoic acid, 2-ethylpentanoic acid and 2isopropylpentanoic acid were not more than $2.0 \%$.

3.2.3. Linearity. The linearity of the method was evaluated by analyzing eight solutions in the concentration range between 50 to $400 \mu \mathrm{g} / \mathrm{mL}$ for each solution of valproic acid and its related impurities. The peak areas obtained from different 


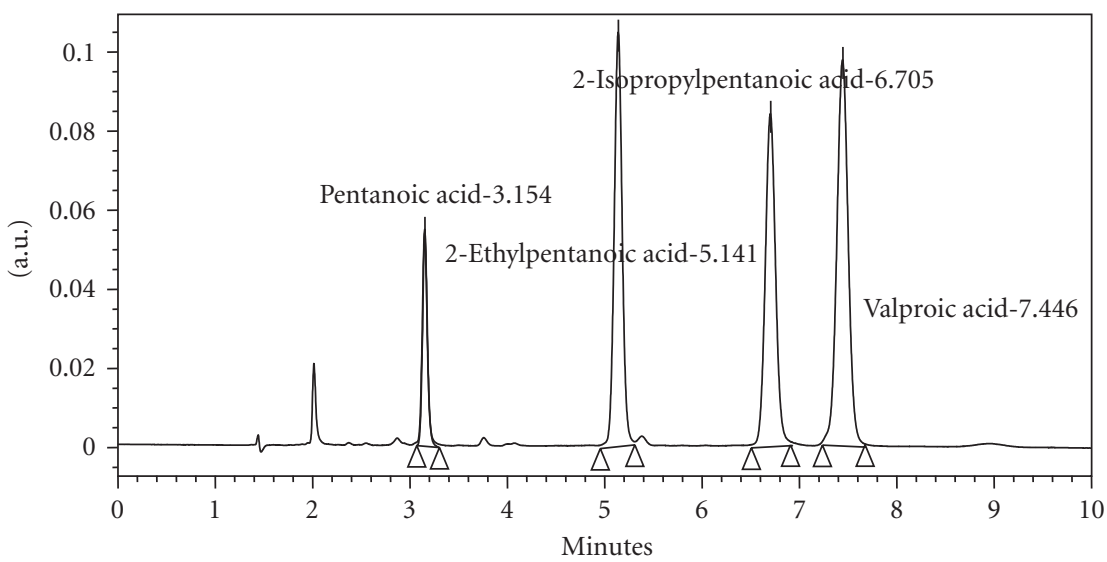

(a)

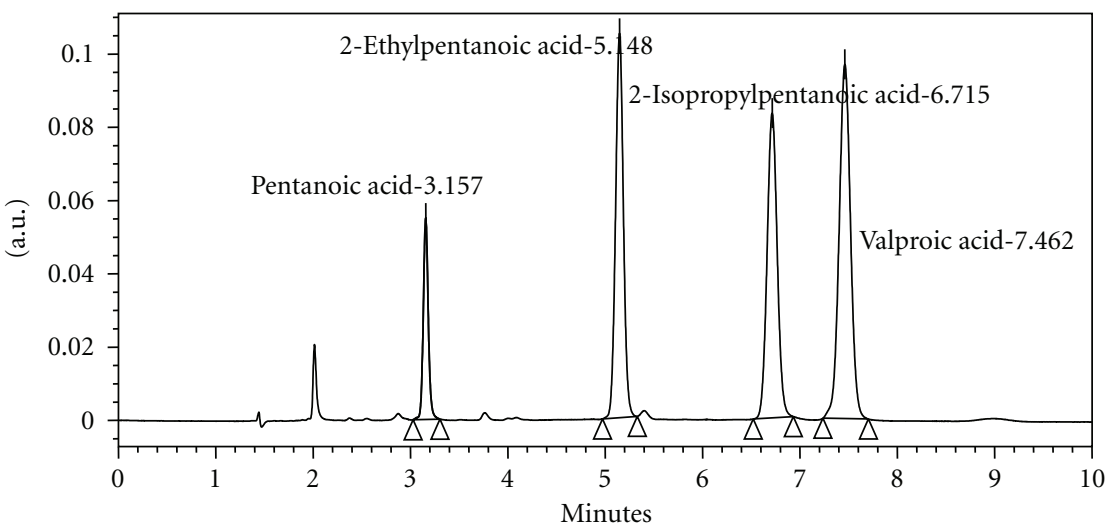

(b)

FIGURE 2: Chromatograms of working standards and sample of valproic acid with its related impurities, where (a) chromatograms of reference standard of valproic acid $(0.2 \mathrm{mg} / \mathrm{mL})$ and impurities $(0.2 \mathrm{mg} / \mathrm{mL})$. (b) Chromatograms of sample of valproic acid $(0.2 \mathrm{mg} / \mathrm{mL})$ and impurities $(0.2 \mathrm{mg} / \mathrm{mL})$.

TABLE 2: Data for intermediate precision.

\begin{tabular}{lcccc}
\hline & \multicolumn{5}{c}{ Area } \\
Injection & PA & 2-EPA & 2-IsoPPA & VPA \\
\hline SET 01 & 210954.0 & 623938.5 & 629944.0 & 813293.0 \\
SET 02 & 208416.5 & 616521.5 & 623969.5 & 799387.0 \\
SET 03 & 208213.0 & 617099.5 & 621781.0 & 800629.0 \\
SET 04 & 208638.5 & 615928.5 & 622960.5 & 799801.5 \\
SET 05 & 210549.5 & 626428.0 & 631619.5 & 813999.0 \\
SET 06 & 211420.5 & 636014.5 & 636014.5 & 818790.0 \\
Mean & 209698.7 & 622655.1 & 627714.8 & 807649.9 \\
Std dev & 1431.1 & 7849.7 & 5673.5 & 8665.1 \\
\% CV & 0.7 & 1.3 & 0.9 & 1.1 \\
\hline
\end{tabular}

concentrations of the drugs were used to calculate linear regression equations. These equations are $y=211.6 x-1217$, $y=238.6 x+12028, y=250.4 x-8400$, and $y=321.8 x-$ 7153 with correlation coefficients of $R^{2}=0.998, R^{2}=0.997$, $R^{2}=0.999$ and $R^{2}=0.99$ for pentanoic acid, 2-ethylpentanoic acid, 2-isopropylpentanoic acid and valproic acid,
TABle 3: Data for robustness.

\begin{tabular}{lcccc}
\hline & \% CV & & & \\
Condition & PA & 2-EPA & 2-IsoPPA & VPA \\
\hline Column change & 0.1 & 0.1 & 0.2 & 0.1 \\
MP ratio change $(56: 44)$ & 0.9 & 0.05 & 0.1 & 0.4 \\
MP ratio change $(54: 66)$ & 0.5 & 0.8 & 0.3 & 0.1 \\
Flow rate change $(1.10 \mathrm{~mL} / \mathrm{min})$ & 1.6 & 1.4 & 1.1 & 0.6 \\
Flow rate change $(1.3 \mathrm{~mL} / \mathrm{min})$ & 1.4 & 0.3 & 0.2 & 0.1 \\
\hline
\end{tabular}

respectively. The high values of the correlation coefficients are indicative of linear relationships between the analyte concentration and peak area.

3.2.4. Limit of Detection and Limit of Quantification. The limit of detection (LOD) and limit of quantification (LOQ) were established by evaluating the minimum level at which the analyte could be readily detected and quantified accurately. The LOD and LOQ for each component are $0.5 \mu \mathrm{g} / \mathrm{mL}$ and $2.0 \mu \mathrm{g} / \mathrm{mL}$, respectively. Signal-to-noise ratio is more than 3.3 for LOD and more than 10 for LOQ. 
TABLE 4: Summary of validation results observed by the proposed method.

\begin{tabular}{|c|c|c|c|c|}
\hline Parameter & $\mathrm{PA}$ & 2-EPA & 2-IsoPPA & VPA \\
\hline $\mathrm{LOD}(\mu \mathrm{g} / \mathrm{mL})$ & 0.5 & 0.5 & 0.5 & 0.5 \\
\hline $\mathrm{LOQ}(\mu \mathrm{g} / \mathrm{mL})$ & 2.0 & 2.0 & 2.0 & 2.0 \\
\hline Accuracy (\%) & $99.12-99.80$ & $98.27-101.1$ & $100.01-101.9$ & $98.56-101.35$ \\
\hline \multicolumn{5}{|l|}{ Precision (RSD, \%) } \\
\hline Method precision & 0.61 & 1.21 & 0.90 & 1.07 \\
\hline Intermediate precision & 0.91 & 0.33 & 0.56 & 1.34 \\
\hline \multicolumn{5}{|l|}{ Linearity } \\
\hline Range $(\mu \mathrm{g} / \mathrm{mL})$ & $50-400$ & $50-400$ & $50-400$ & $50-400$ \\
\hline Correlation coefficient & 0.998 & 0.997 & 0.999 & 0.995 \\
\hline Slope & 211.6 & 238.6 & 250.4 & 321.8 \\
\hline Intercept & -1217 & 12028 & -8400 & -7153 \\
\hline Theoretical plate & 35426 & 21329 & 17200 & 31128 \\
\hline Asymmetry & 1.06 & 1.23 & 1.02 & 1.31 \\
\hline
\end{tabular}

3.2.5. Selectivity. The selectivity of the method was evaluated by injecting blank matrix, each individual impurity, the valproic acid standard solution, and the spiked solution to check the interference of the diluent as well as the standard solution on each other. The method is proved to be highly selective that there is no interference on any component.

3.2.6. Robustness. The influence of five $(k)$ chromatographic parameters on the separation was investigated. The parameters examined were the amount of ACN in the mobile phases, the amount of buffer solution in the mobile phases, different column lots, different flow rates, and difference in $\mathrm{pH}$ of buffer. There is no such impact of the small changes on the above parameters observed which suggests that the method is highly robust. The results obtained are shown in Table 3.

\section{Conclusions}

The proposed isocratic ion-pair UPLC method shows a good separation of valproic acid from its impurities present in bulk drug. The robustness study indicates that mainly the amount of ion pair reagent in the mobile phase solution should be monitored carefully to ensure the best chromatography since this has a significant effect on the separation. The method was shown to be selective, precise, sensitive, and linear which is proven by the result of the validation summary shown in Table 4. The method can be used for the quantification of valproic acid and their pharmacopeial-related impurities. It can be applicable for the analysis of drug substances and drug products in pharmaceutical dosage form also.

\section{Acknowledgments}

The authors are grateful to the National Facility for Drug Discovery through NCEs Development \& Instrumentation Support for Small Manufacturing Enterprises, Department of Chemistry, Saurashtra University, Rajkot, India, for providing analytical facilities. The authors are also thankful to the M/s Parth laboratories Pvt. Ltd., Rajkot, India, for providing working standards.

\section{References}

[1] T. R. Henry, "The history of valproate in clinical neuroscience," Psychopharmacology Bulletin, vol. 37, supplement 2, pp. 5-16, 2003.

[2] G. Rosenberg, "The mechanisms of action of valproate in neuropsychiatric disorders: can we see the forest for the trees?" Cellular and Molecular Life Sciences, vol. 64, no. 16, pp. 20902103, 2007.

[3] E. Posner and N. Lorenzo, Posttraumatic epilepsy, 2006, http://www.emedicine.com/NEURO/topic318.htm.

[4] MediLexicon International Ltd, FDA Issues Approvable Letter for Stavzor Delayed Release Valproic Acid Capsules, 2007, http://www.medicalnewstoday.com/articles/86674.php.

[5] M. Shiba, S. Hashi, H. Nakanishi, S. Masuda, T. Katsura, and I. Yano, "Detection of 22 antiepileptic drugs by ultraperformance liquid chromatography coupled with tandum mass spectrometry applicable to routine therapeutic drug monitoring," Biomedical Chromatography, vol. 26, pp. 15191528, 2012.

[6] P. N. Yat, I. Odidi, A. Odidi et al., "A rapid and simple stabilityindicating HPLC method for the analysis of valproic acid in divalproex sodium formulations," Pharmacopeial Forum, vol. 30, no. 6, pp. 2281-2294, 2004.

[7] V. Ioffe, T. Kalendarev, I. Rubinstein, and G. Zupkovitz, "Reverse phase HPLC for polar lipids. Simple and selective HPLC procedures for analysis of phospholipid-based derivatives of valproic acid and various non-steroidal antiinflammatory drugs," Journal of Pharmaceutical and Biomedical Analysis, vol. 30, no. 3, pp. 391-403, 2002.

[8] L. S. W. Steijns, J. Bouw, and J. Van der Weide, "Evaluation of fluorescence polarization assays for measuring valproic acid, phenytoin, carbamazepine and phenobarbital in serum," Therapeutic Drug Monitoring, vol. 24, no. 3, pp. 432-435, 2002.

[9] C. A. Lau-Cam and R. W. Roos, "HPLC method with precolumn phenacylation for the assay of valproic acid and its salts in pharmaceutical dosage forms," Journal of Liquid Chromatography and Related Technologies, vol. 20, no. 13, pp. 20752087, 1997. 
[10] H. Liu, L. J. Forman, J. Montoya, C. Eggers, C. Barham, and M. Delgado, "Determination of valproic acid by high-performance liquid chromatography with photodiode-array and fluorescence detection," Journal of Chromatography, vol. 576, no. 1, pp. 163-169, 1992.

[11] M. A. Farajzadeh, K. Farhadi, A. A. Matin, P. Hashemi, and A. Jouyban, "Headspace solid-phase microextraction-gas chromatography method for the determination of valproic acid in human serum, and formulations using hollow-fiber coated wire," Analytical Sciences, vol. 25, no. 7, pp. 875-879, 2009.

[12] P. Shahdousti, A. Mohammadi, and N. Alizadeh, "Determination of valproic acid in human serum and pharmaceutical preparations by headspace liquid-phase microextraction gas chromatography-flame ionization detection without prior derivatization," Journal of Chromatography B, vol. 850, no. 1-2, pp. 128-133, 2007.

[13] C. Deng, N. Li, J. Ji, B. Yang, G. Duan, and X. Zhang, "Development of water-phase derivatization followed by solid-phase microextraction and gas chromatography/mass spectrometry for fast determination of valproic acid in human plasma," Rapid Communications in Mass Spectrometry, vol. 20, no. 8, pp. 1281-1287, 2006.

[14] R. L. Dills and D. D. Shen, "Methods to reduce background interferences in electron-capture gas chromatographic analysis of valproic acid and its unsaturated metabolites after derivatization with pentafluorobenzyl bromide," Journal of Chromatography B, vol. 690, no. 1-2, pp. 139-152, 1997.

[15] W. Czarnecki and B. Hałczyńska, "Colorimetric determination of valproic acid and its salts," Acta Poloniae Pharmaceutica, vol. 56, no. 5, pp. 353-355, 1999.

[16] K. Matsuura, T. Ohmori, M. Nakamura, Y. Itoh, and K. Hirano, "A simple and rapid determination of valproic acid in human plasma using a non-porous silica column and liquid chromatography with tandem mass spectrometric detection," Biomedical Chromatography, vol. 22, no. 4, pp. 387-393, 2008.

[17] D. S. Jain, G. Subbaiah, M. Sanyal, and P. Shrivastav, "A high throughput and selective method for the estimation of valproic acid an antiepileptic drug in human plasma by tandem LC-MS/MS," Talanta, vol. 72, no. 1, pp. 80-88, 2007.

[18] H. Amini, M. Javan, and A. Ahmadiani, "Development and validation of a sensitive assay of valproic acid in human plasma by high-performance liquid chromatography without prior derivatization," Journal of Chromatography B, vol. 830, no. 2, pp. 368-371, 2006.

[19] V. Pucci, E. Monteagudo, and F. Bonelli, "High sensitivity determination of valproic acid in mouse plasma using semiautomated sample preparation and liquid chromatography with tandem mass spectrometric detection," Rapid Communications in Mass Spectrometry, vol. 19, no. 24, pp. 3713-3718, 2005.

[20] M. C. Lin, H. S. Kou, C. C. Chen, S. M. Wu, and H. L. Wu, "Simple and sensitive fluorimetric liquid chromatography method for the determination of valproic acid in plasma," Journal of Chromatography B, vol. 810, no. 1, pp. 169-172, 2004.

[21] P. Kishore, V. Rajani Kumar, V. Satyanarayana, and D. R. Krishna, "HPLC determination of valproic acid in human serum," Pharmazie, vol. 58, no. 6, pp. 378-380, 2003.

[22] M. D. Rukhadze, M. V. Gonashvili, A. N. Zirakishvili, and N. V. Okudzhava, "HPLC determination of valproic acid as bromophenacyl ester in blood plasma," Pharmaceutical Chemistry Journal, vol. 36, no. 1, pp. 45-47, 2002.
[23] S. Hara, M. Kamura, K. Inoue, M. Fukuzawa, N. Ono, and T. Kuroda, "Determination of valproic acid in human serum by high-performance liquid chromatography with fluorescence detection," Biological and Pharmaceutical Bulletin, vol. 22, no. 9, pp. 975-977, 1999.

[24] C. Lucarelli, P. Villa, E. Lombaradi, P. Prandini, and A. Brega, "HPLC method for the simultaneous analysis of valproic acid and other common anticonvulsant drugs in human plasma or serum," Chromatographia, vol. 33, no. 1-2, pp. 37-40, 1992.

[25] L. J. Lovett, G. A. Nygard, and G. R. Erdmann, "HPLC determination of valproic acid in human serum using ultraviolet detection," Journal of Liquid Chromatography, vol. 10, no. 4, pp. 687-699, 1987.

[26] F. A. L. Van der Horst, G. G. Eikelboom, and J. J. M. Holthuis, "High-performance liquid chromatographic determination of valproic acid in plasma using a micelle-mediated pre-column derivatization," Journal of Chromatography A, vol. 456, pp. 191-199, 1986.

[27] L. Budáková, H. Brozmanová, F. Kvasnička, and M. Grundmann, "Determination of valproic acid by on-line coupled capillary isotachophoresis with capillary zone electrophoresis with conductometric detection," Ceska a Slovenska Farmacie, vol. 56, no. 5, pp. 249-253, 2007.

[28] G. K. Belin, S. Krähenbühl, and P. C. Hauser, "Direct determination of valproic acid in biological fluids by capillary electrophoresis with contactless conductivity detection," Journal of Chromatography B, vol. 847, no. 2, pp. 205-209, 2007.

[29] V. Pucci, R. Mandrioli, and M. A. Raggi, "Determination of valproic acid (2-propylpentanoic acid) in human plasma by capillary electrophoresis with indirect UV detection," Electrophoresis, vol. 24, no. 12-13, pp. 2076-2083, 2003.

[30] J. Jin, T. Wang, and S. F. Y. Li, "Indirect laser-induced fluorescence detection of Valproic Acid in human serum by capillary electrophoresis," Electrophoresis, vol. 20, pp. 18561861, 1999. 


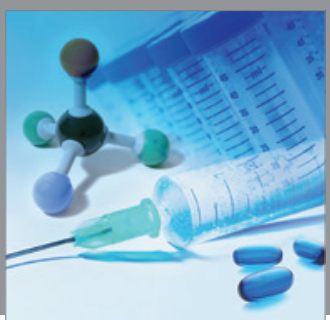

International Journal of

Medicinal Chemistry

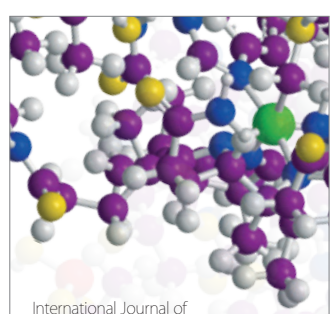

Carbohydrate Chemistry

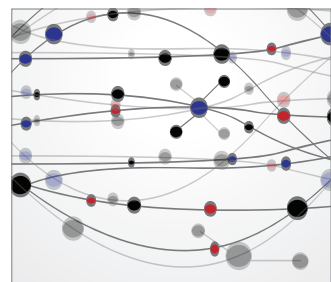

The Scientific World Journal
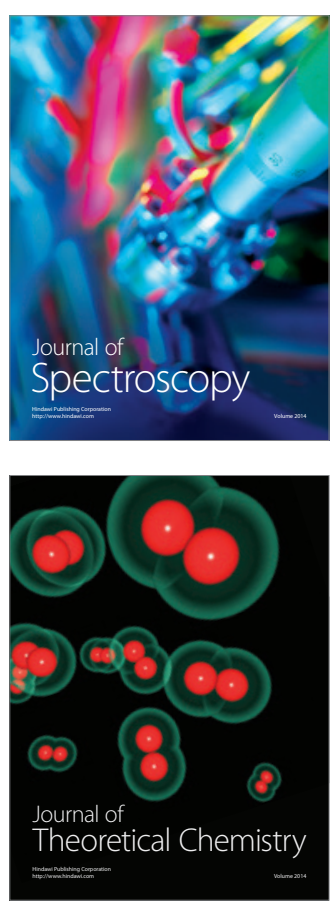
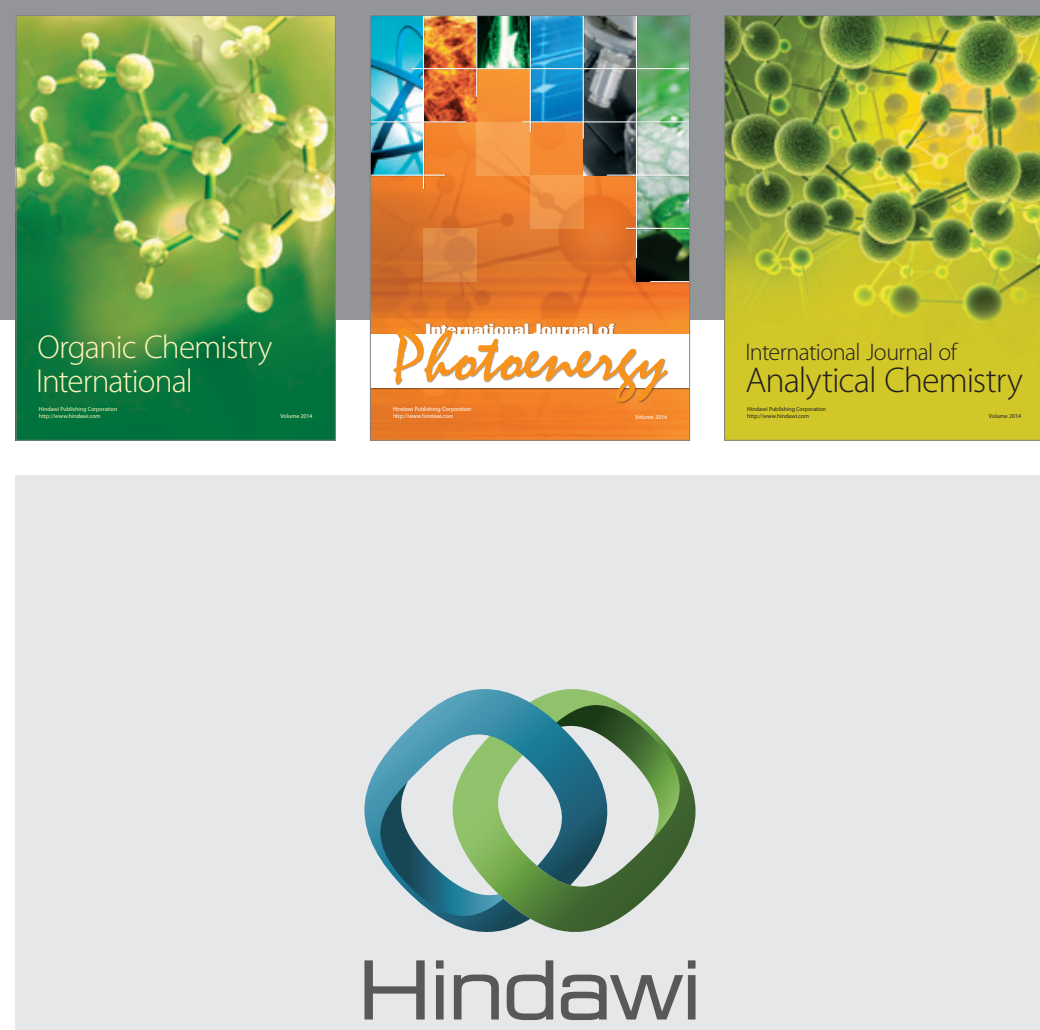

Submit your manuscripts at

http://www.hindawi.com
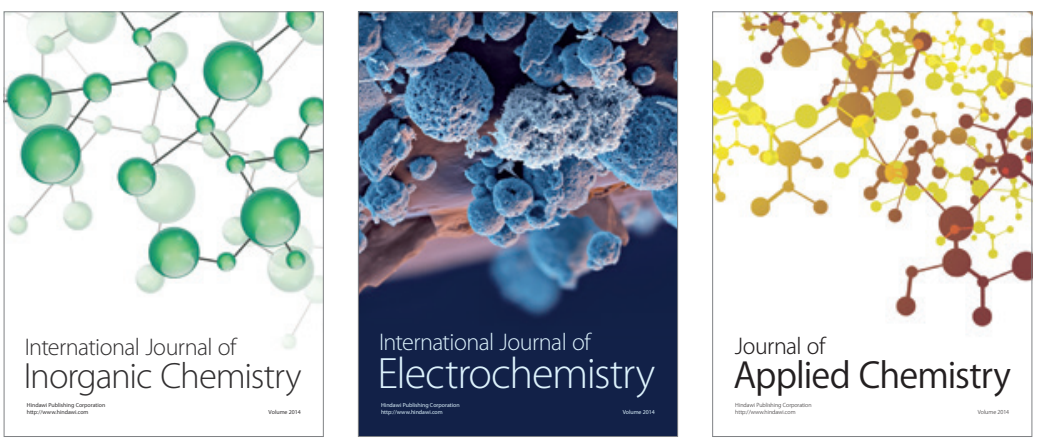

Journal of

Applied Chemistry
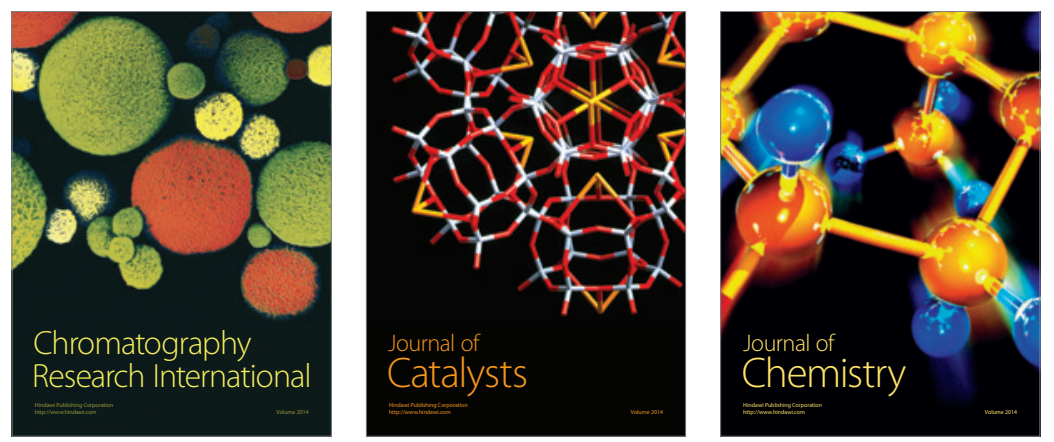
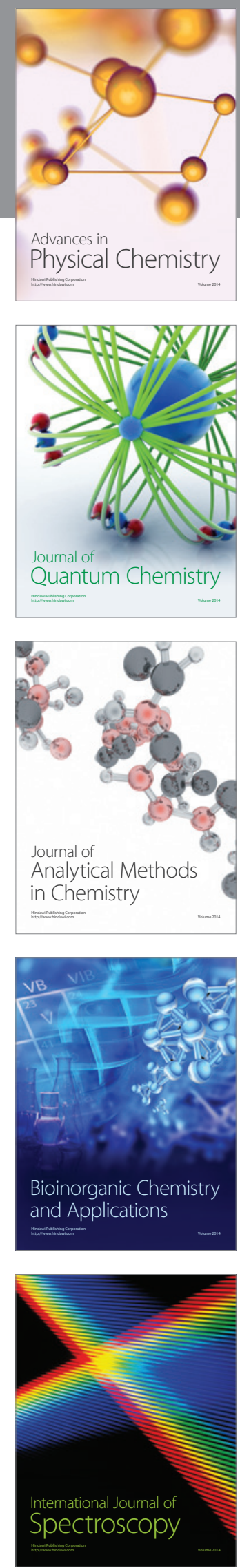